\title{
Effects of Selective Laser Melting additive manufacturing parameters of Inconel 718 on porosity, microstructure and mechanical properties
}

\author{
K. Moussaoui ${ }^{\mathrm{a}, *}$, W. Rubio ${ }^{\mathrm{a}}$, M. Mousseigne ${ }^{\mathrm{a}}$, T. Sultan ${ }^{\mathrm{b}}$, F. Rezai ${ }^{\mathrm{c}}$ \\ a Institut Clément Ader, 3 Rue Caroline Aigle, 31400 Toulouse, France \\ ${ }^{\mathrm{b}}$ Prismadd, 2 Impasse Georges Courteline, 82000 Montauban, France \\ ${ }^{\mathrm{c}}$ Ecole des Mines d'Albi, Campus Jarlard, 81013 Albi cedex 09, France
}

\begin{abstract}
A B S T R A C T
The effect of SLM parameters on porosity, microstructure and mechanical properties is studied. To this purpose, the Selective Laser Melting (SLM) technology is applied to manufacture Inconel 718 specimens. The material, the manufacturing process, the Hot Isostatic Pressure (HIP), heat treatment, observation procedures and characterisation of mechanical properties are presented. A columnar-dendritic microstructure was observed on all the SLM specimens and a Volumetric Energy Density (VED) effect on the latter was also noted. The rate of porosity varies in relation to the VED and is considerably reduced after HIP. The heat treatment erases the dendritic microstructure, significantly enhances microhardness and confers on the alloy tensile mechanical properties comparable to forged Inconel 718.
\end{abstract}

\section{Keywords:}

Selective Laser Melting

Inconel 718

Porosity

Microstructure

Mechanical properties

\section{Introduction}

The aeronautical, aerospace and nuclear industries have applications for which the use of conventional materials is no longer a valid option. They are then replaced by what are known as Ni-base superalloys, characterised by the conservation of their mechanical properties at high temperatures [1-3]. Among these is Inconel 718 that can be used up to a temperature of $650^{\circ} \mathrm{C}$ without any prejudicial reduction in its mechanical properties while still retaining excellent resistance to corrosion and fatigue $[4,5]$. For this reason, it is chosen to manufacture parts whose operating temperatures are extremely high. However, it is difficult to manufacture workpieces from Inconel 718 using conventional machining methods due to the significant level of wear to which the cutting tools are subjected and the reduced rate of material removal $[6,7]$.

Blanther, in 1892, was the first to file a patent relating to additive manufacturing [8]. However, it took until the 1980s for this process to be adopted by industrialists [9]. Using this method, extremely complex workpieces can be manufactured from a CAD file and without the need to use moulds and/or cutting tools. This provides an avenue for unlimited creativity in designing parts and helps save time and reduce costs and material consumed as compared with traditional processes $[10,11]$. Since the 1980s, additive manufacturing has developed spectacularly and some would argue that it is the manufacturing process that has been the most rapidly developed in the world $[12,13]$.
Selective Laser Melting (SLM) is a powder-bed based technology in the additive manufacturing category. On manufacturing, a fine layer of metallic powder is deposited on a plate, then a high energy laser scans the layer to melt it locally in pre-defined zones. Once the first layer has been completed, the plate moves down and a second layer of metallic powder is deposited and so on until complete manufacturing of the desired part. This method allows geometrically complex workpieces with great dimensional accuracy and fine surface condition to be produced [14].

Some studies have focused on the microstructure of Inconel 718 obtained by SLM. Amato et al. [15] observe on blank SLM specimens a development of grains and columnar microstructures that are essentially parallel to the build direction. The SLM process produces a fine columnar-dendritic microstructure that is generated by the extremely rapid cooling speeds [16]. It also produces parts with a high level of porosity [16], mechanical properties (mainly in fatigue) that are reduced compared with conventional processes and a high surface roughness value [17]. This explains why SLM blanks have to be subjected to various post-treatments to reduce porosity and enhance mechanical properties. Hot Isostatic Pressing (HIP) is one post-treatment that combines a high temperature and strong pressure to reduce the porosity level. Studies have shown the beneficial effect of HIP on the porosity level ( $\mathrm{HIP}$ at $1150{ }^{\circ} \mathrm{C}-100 \mathrm{MPa}$ : density varying between 99.985\% and 99.989\%) [18,19]. After HIP, ageing heat treatment is generally recommended for Inconel 718 : $720^{\circ} \mathrm{C}$ for $8 \mathrm{~h}$ and $620^{\circ} \mathrm{C}$ for

\footnotetext{
* Corresponding author.

E-mail address: kamel.moussaoui@univ-tlse3.fr (K. Moussaoui).
} 
$8 \mathrm{~h}$ [4]. This treatment ensures the germination and growth of hardening phases $\gamma^{\prime}$ and $\gamma^{\prime \prime}$. After ageing heat treatment, the dendritic microstructure disappears, a needle-shaped $\delta$ phase precipitates at the grain boundaries, the Laves phase and carbides emerge and $\gamma^{\prime}$ and $\gamma^{\prime \prime}$ phases disperse and precipitate further in matrix to strengthen the alloy [16]. Parts made of Inconel 718 obtained by SLM and that are then subjected to HIP and heat treatment as described above, can significantly enhance their mechanical properties as compared with SLM blanks and compare with or even outperform forged Inconel 718 parts $[20,15,1,12,16]$.

Hanzl et al. [21] explain that the laser velocity and power parameters have most impact on tensile mechanical properties. Their combination also affects the microstructure and the melt pool, including the surface. The various combinations of these two parameters may produce perfectly uniform surfaces or porous structures. Some studies have tested other parameters, such as the size of the laser, the thickness of the layer deposited and the distance of the scan lines for the various materials like steel 316L [22], Ti6Al4V [23] and Inconel 718 $[24,13,25]$. In reality, the workpiece's final quality will depend on the combination of all these parameters. Through their experimental results, Gu et al. [26] observe that the power, velocity, the thickness of the deposited layer and the distance between the scan lines have a considerable influence on densification and the microstructural characteristics during the SLM process. In order to evaluate the combined effect of these parameters, they propose a factor known as "Volumetric Energy Density (VED)" expressed in $\mathrm{J} / \mathrm{m}^{3}$. Other studies use VED to take into account the combined effect of the parameters mentioned above $[27,28]$. Sadowski et al. [29] seek to optimise the quality of the SLM process for Inconel 718 and use the factor known as "Linear Energy Density (LED)", which is the ratio between the laser power and the velocity to qualify the melt pool. They observe that when LED increases from 33 to $1500 \mathrm{~J} / \mathrm{m}$, the melt pool width increases from 100 to $520 \mu \mathrm{m}$ and its depth increases from 13 to $300 \mu \mathrm{m}$. Jia et al. [30] note the same LED impact on densification and recommend a LED of $330 \mathrm{~J} / \mathrm{m}$ for a densification of $98.4 \%$ when manufacturing Inconel 718 . They also took an interest in the microhardness and the microstructure. As far as microhardness is concerned, they observe an increase in the latter with the increase in LED. As for the microstructure, they report that it undergoes successive changes: from coarse columnar dendrites to grouped dendrites, then fine and uniformly distributed cylindrical dendrites, with the increase in LED.

It is, however, important to note that although the basic concepts apply, the change in materials and change in the type of machine will create workpieces that are different in terms of porosity levels and mechanical properties. For this article it was decided to study the effect of the SLM parameters (laser power, velocity, distance between scan lines) through the "Volumetric Energy Density (VED)" on several criteria such as roughness, the porosity rate, the microstructure and mechanical properties. Indeed, few studies to our knowledge concern the effect of VED on the criteria mentioned above. The originality of this work lies in the influence of several VED on roughness, porosity rate, microstructure, microhardness and mechanical properties. Microstructure, microhardness and porosity rate were analysed before and after HIP + heat treatment while the mechanical properties were analysed after HIP + heat treatment.

\section{Material and methods}

The powder used in this study is a nickel alloy powder, Inconel 718.

Table 1

Chemical composition of Inconel 718 powder.

\begin{tabular}{llllllll}
\hline Element & $\mathrm{Ni}$ & $\mathrm{Cr}$ & $\mathrm{Fe}$ & $\mathrm{Nb}$ & $\mathrm{Mo}$ & $\mathrm{Ti}$ & $\mathrm{Al}$ \\
\hline $\mathrm{wt} \%$ & 54.19 & 20.58 & \multirow{2}{*}{15.14} & 5.13 & 3.04 & 0.95 & 0.67 \\
\hline
\end{tabular}

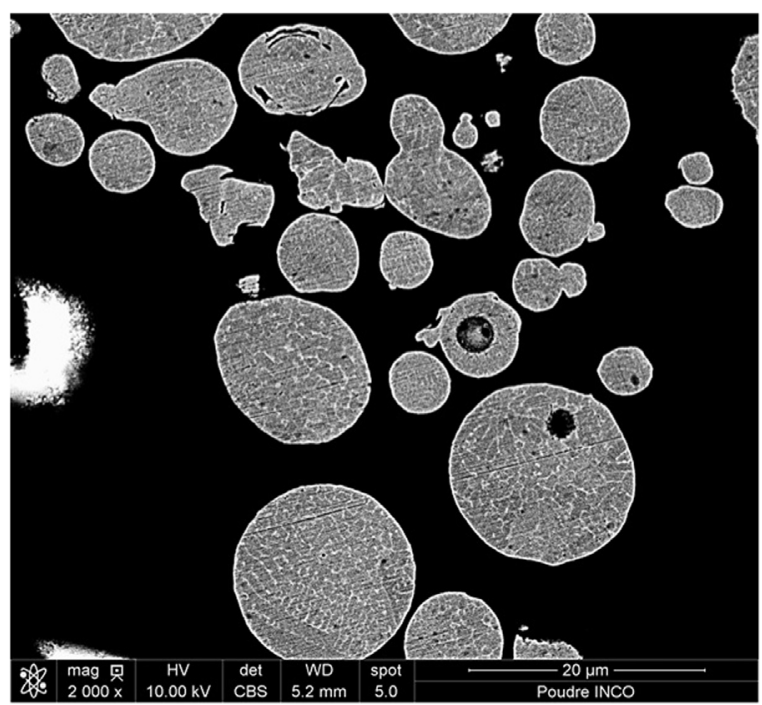

Fig. 1. SEM metallographic image of powder etched cross-section showing the internal microdendritic microstructure and pores in particles.

Table 1 and Fig. 1 show the chemical composition and the metallography of the powder used. The manufacturer's grain size indicates that the size of the particles is between 5 and $25 \mu \mathrm{m}$. This grain size was verified using the laser method. This is a technique using the optical properties derived from the interaction between a set of particles and an incident laser beam to obtain the size distribution for the set analysed. The results are shown in Fig. 2. The particles are not very spherical and there is the presence of pores within the particles.

The powder bed laser melt additive manufacturing machine is a DMP PROX300. This machine has a YAG type laser with max. power of $450 \mathrm{~W}$ and a spot diameter of $70 \mu \mathrm{m}$. Manufacturing is performed in a protected atmosphere filled with argon (Ar). It has an automatic powder supply system and a manufacturing plate. The manufacturing process is as follows: (i) a fine layer of Inconel 718 powder is deposited by the roller; (ii) the layer of Inconel 718 powder is melted by the incident laser beam so it binds with the already solidified zones of the layer beneath; (iii) the manufacturing plate is moved down by the thickness of one layer for a new deposit of powder and new laser fusion. The laser strategy used is shown in Fig. 3. This strategy combines a different scan on each layer, with the laser scanning alternatively along the $\mathrm{X}$ and $\mathrm{Y}$ axes. This means that layer $\mathrm{n}$ will have the scan direction along the $\mathrm{X}$-axis while layer $\mathrm{n}+1$ will be rotated by $90^{\circ}$ and will be along the Y-axis.

In order to observe the influence of the SLM parameters on some of the previously mentioned criteria, 35 cubes with dimensions $20 * 20 * 20 \mathrm{~mm}$ were produced (Fig. 4). The power P was varied from 150 to $450 \mathrm{~W}$, the velocity V from 1000 to $1800 \mathrm{~mm} / \mathrm{s}$ and the scan

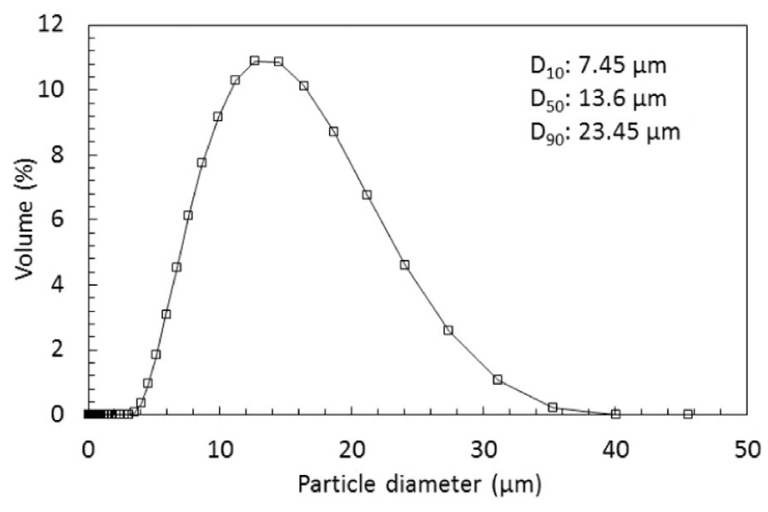

Fig. 2. Particle size distribution of Inconel 718. 


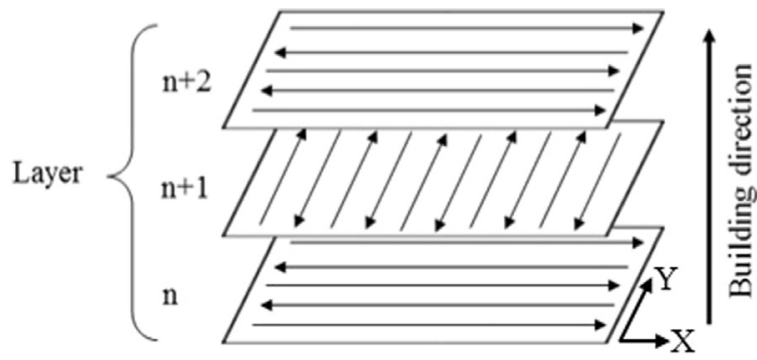

Fig. 3. Laser scanning strategy used in SLM experiments.

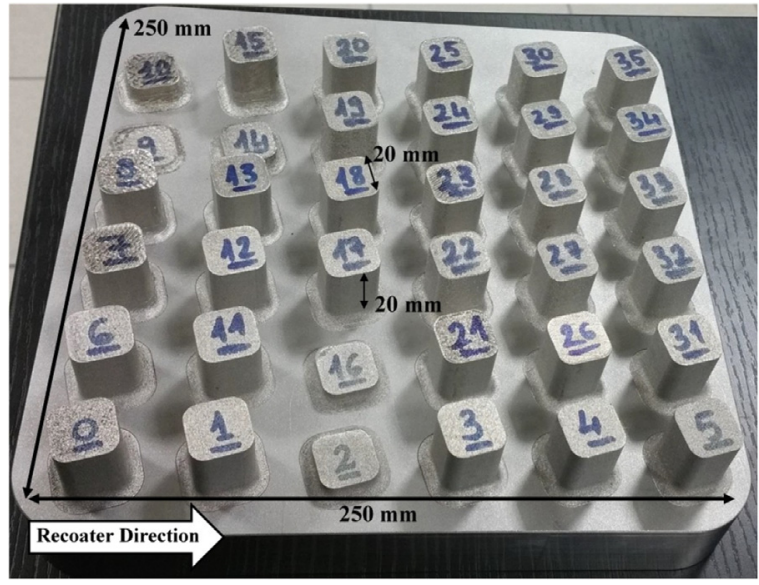

Fig. 4. Inconel 718 specimen model.

Table 2

Parameters of SLM for the 8 cubes.

\begin{tabular}{ll}
\hline $\begin{array}{l}\text { Specimen } \\
\text { number }\end{array}$ & $\begin{array}{l}\text { VED } \\
\left(\mathrm{J} / \mathrm{mm}^{3}\right)\end{array}$ \\
\hline 12 & 40.8 \\
13 & 51 \\
17 & 31.75 \\
18 & 39.7 \\
26 & 40.8 \\
29 & 61.2 \\
31 & 31.75 \\
34 & 47.6 \\
\hline
\end{tabular}

distance (hatching $\mathrm{H}$ ) from 50 to $90 \mu \mathrm{m}$. The layer thickness (d) was set at $70 \mu \mathrm{m}$. Analysis of cubes (2-9-10-14-16) did not prove possible as their production was not completed (see Fig. 4). The VED used did not build these cubes because the VED is too low (not enough fusion) or is too high (too much fusion). Out of the remaining 31 cubes, 9 were eliminated for appearance reasons. Indeed, major defects and significant rough spots were observed, indicating a very poor melt quality. 21 cubes were retained after this visual observation (cubes 1-3-4-5-11-12-13-17-18-19-20-26-27-28-29-30-31-32-33-34-35). Roughness appeared to be a good indicator of melt quality, which is why it was chosen as a selection criterion for the 21 remaining cubes. Surface roughness Sa was analysed on the top face (normal to $\mathrm{Z}$ ) and the side of the cube. Only roughness results concern the 21 cubes. Indeed, the

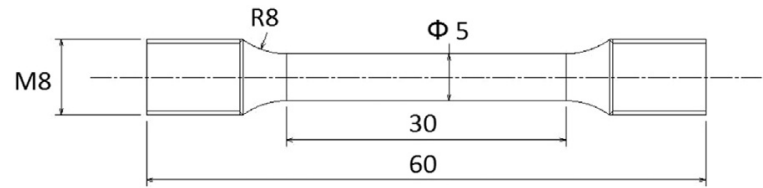

Fig. 5. Geometry and dimensions of the tensile specimens. roughness criterion allowed 8 cubes (12-13-17-18-26-29-31-34) to be selected to refine observations on level of porosity, microstructure and mechanical properties. The SLM parameters of the 8 cubes are shown in Table 2. The VED was calculated using Eq. (1) where $\mathrm{P}$ is the power in $\mathrm{W}$, $\mathrm{V}$ the scan velocity in $\mathrm{mm} / \mathrm{s}, \mathrm{H}$ the scan distance in $\mu \mathrm{m}$ and $\mathrm{d}$ the thickness of the layer deposited in $\mu \mathrm{m}$. The VED will be expressed in $\mathrm{J} /$ $\mathrm{mm}^{3}$.

$V E D=\frac{P}{V \cdot H \cdot d} \times 10^{6}$

The surface roughness measurements were performed using an ALICONA Infinite-FocusSL optical system. The metallographic observations were performed on an Olympus optical microscope and a NOVA NanoSEM450 Scanning Electron Microscope (SEM). The specimens were polished and then etched with aqua regia $(70 \% \mathrm{HCl}+30 \%$ HNO3) to observe the microstructure. The chemical composition was analysed using the Energy Dispersive Spectroscopy (EDS) method. Microhardness measurements were performed on a Buehler Micromet 5100 series system with a load of $200 \mathrm{~g}$ and each value was averaged out over three measurements. The heat treatment used in this study was an HIP $\left(1160^{\circ} \mathrm{C}, 102 \mathrm{MPa}, 3 \mathrm{~h}\right.$ and air cooling) followed by solution treatment $\left(980^{\circ} \mathrm{C}, 1 \mathrm{~h}\right.$ and air cooling) and double ageing $\left(720^{\circ} \mathrm{C}, 8 \mathrm{~h}\right.$, furnace cooling $+620^{\circ} \mathrm{C}, 8 \mathrm{~h}$ and air cooling). Tensile tests were performed on an Instron 8561 machine at ambient temperature. The geometry and dimensions of the tensile test specimens are shown in Fig. 5. These tensile test specimens were manufactured in two series: series A $\left(0^{\circ}\right)$ parallel to the Z-axis build and series B $\left(90^{\circ}\right)$ normal to the Z-axis build (along X). They are made from cylindrical specimens. They then underwent the heat treatment described previously and were machined. The level of porosity was established by processing of the images obtained by optical microscopy. 10 images were taken for each specimen randomly over the entire manufacturing plane (XY plane). On each image there are between 200 and 250 pores, thus meaning in total between 2000 and 2500 pores measured for each specimen to determine the level of porosity. The drawback with this method was the considerable effort that had to be devoted to preparation of the specimens.

\section{Results and discussion}

\subsection{Roughness}

The results show a roughness Sa going from 6.7 to $35 \mu \mathrm{m}$ on the cube's top face and from 8.5 to $42 \mu \mathrm{m}$ on the cube's side. These values are very close and indicate good uniformity of roughness over the entire cube. A curve is plotted on the graph of Fig. 6 to show some roughness values (cube top face Sa) to observe the effect of the scan velocity $\mathrm{V}$ and power $P$. It can be seen that the increase in velocity and power leads to greater roughness while lower velocities and powers generate less

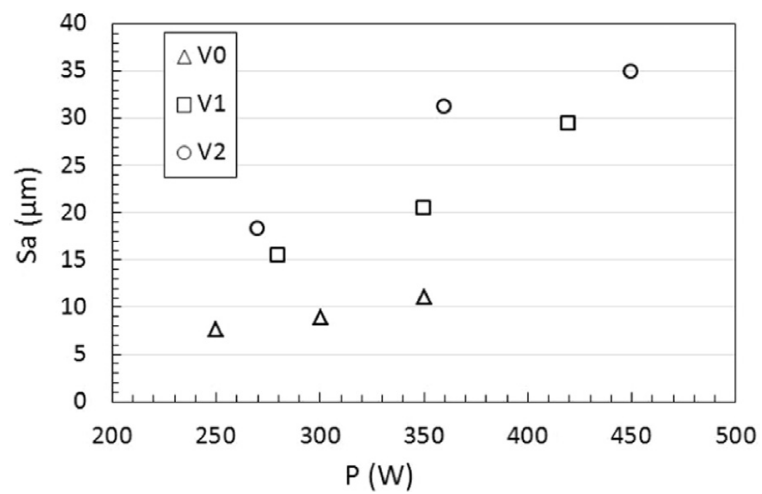

Fig. 6. Effect of power (P) and scanning velocity (V, with $\mathrm{V} 0<\mathrm{V} 1<\mathrm{V} 2$ ) on roughness $\mathrm{Sa}$ of the cube face. 
roughness. No significant hatching effect $\mathrm{H}$ was observed and use of VED was not decisive for roughness. However, it is important to note that the quality of the final surface will depend mainly on the power/ velocity relation.

The following results concern the 8 cubes (12-13-17-18-26 -29-31-34) chosen after the roughness study. These 8 cubes have a roughness Sa of between 6.7 and $15.46 \mu \mathrm{m}$ for the top face of the cube and between 8.5 and $17.6 \mu \mathrm{m}$ for the side of the cube.

\subsection{Microstructures and porosity}

\subsubsection{As-deposited by SLM}

The physics involved during the laser beam melting process of a powder bed is illustrated schematically in Fig. 7. This Figure shows a cross-section of a powder bed on the scale of particles of powder lying on a dense substrate. In the zone where the laser beam reaches the powder bed, the particles of powder are heated extremely rapidly, and the local temperature increases to form a melt pool that will then solidify. Several physical phenomena will intervene and combine to form the final material and its accompanying microstructure.

Fig. 8 shows a 3D cube that is built from the observations on specimen 12 on an optical microscope. The line by line SLM and then layer by layer SLM manufacturing characteristics are clearly visible. On the $\mathrm{XY}$ plane the scanning strategy used in the present study can be observed. The XZ and ZY planes illustrate the morphology of the melt pool. This morphology is in the form of a parabolic arc that indicates a Gaussian energy distribution of the laser. Similar morphologies have been observed for SLM manufacturing of Inconel 718 by other researchers $[12,31]$. This morphology was observed on all the specimens in this study.

Fig. 9 shows a columnar dendritic microstructure that is mainly parallel to the Z-axis build (shown by the white arrow). This microstructure is characteristic of the microstructures obtained by SLM for Inconel 718. It also indicates a very rapid cooling speed of around $10^{5}$ ${ }^{\circ} \mathrm{C} / \mathrm{s}$ [32]. Columnar grains with a cellular structure and columnar grains with very fine dendrites can also be distinguished in this microstructure. The melt pool boundary shows a solidification front from which a different structure can grow (switch to a cellular structure) leading either to a change in orientation of the dendrites or a continuity of the dendrites through the solidification front. The high temperature gradients generate an epitaxial solidification phenomenon [15] that can produce grain growth through several melt pool. All these types of structure can also be observed in a single melt pool (Fig. 9(a)). It can be noted that the melt energy affects more than one layer and will thus melt layers that have already solidified several times. This is a phenomenon that is sought for to bind the layers to each other and make

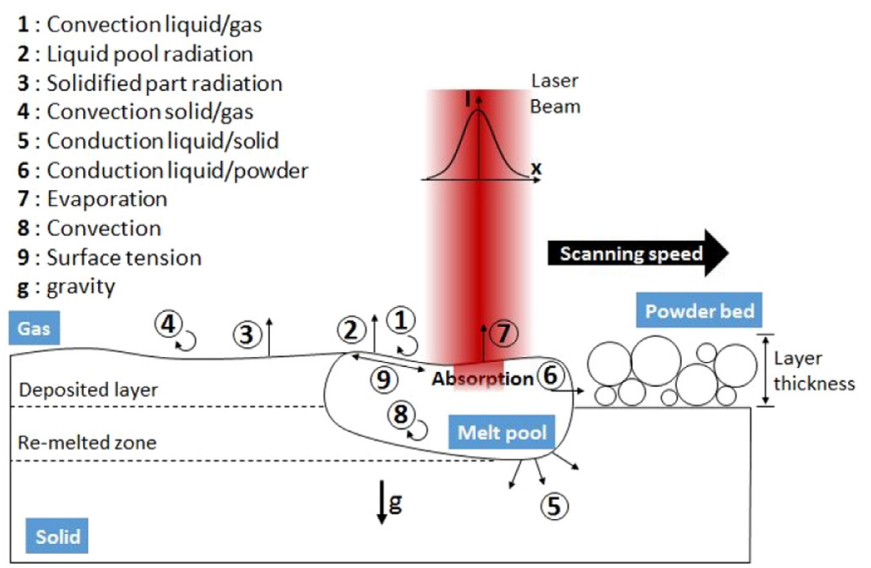

Fig. 7. Schematic overview of the physicals phenomenons that happen in the interaction zone between laser radiation and powder bed.

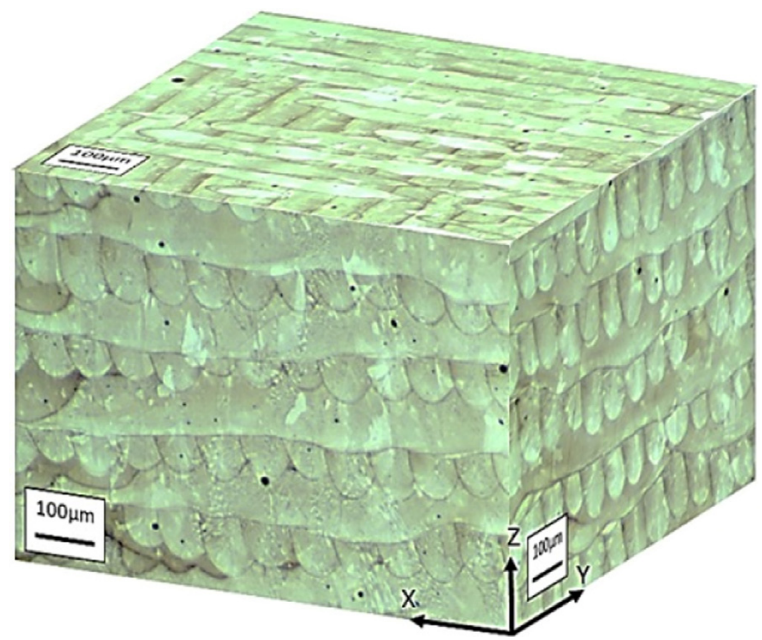

Fig. 8. Optical metallographic image of Inconel 718 in as-built condition in three mutually perpendicular planes of the polished section for specimen 12 . The laser scanning tracks are visible in the 3 planes. The build direction is indicated by $\mathrm{Z}$ axis.

the material more uniform. The increase in VED will lead to a microstructure with longer and very tightly bound dendrites (Fig. 9(b)). Jia et al. [30] note the same effect on the microstructure of Inconel 718 obtained by SLM. Another observation on the effect of the increase in VED on the microstructure relates to the columnar dendrites that seem to be more oriented along the build-axis. The increase of the VED will produce a larger and warmer melt pool. This results in a high thermal gradient and a high cooling rate. This phenomenon will produce fine columnar dendrites. Zhang et al. [31] measured a dendrite spacing of about $0.6 \mu \mathrm{m}$. They tell us that this spacing is small compared to the Inconel obtained by conventional method because of the very high cooling rates in SLM. Mostafa et al. [33], measured a dendrite spacing ranging from 0.6 to $1.25 \mu \mathrm{m}$ in SLM. All these observations are similar for the $\mathrm{ZY}$ plane, while for the XY plane a mainly cellular structure with less dendrites can be seen.

Fig. 10 shows several types of defects: pores by lack of fusion and/or material and spherical pores. What can mainly be seen are spherical pores that were formed during the melt process either by the trapping of protection gases (here Ar) or by the gases generated by melting (sufficiently rapid cooling that traps the metallic vapour). All these types of pores were observed on the three planes. Tillmann et al. [18] showed the presence of argon in the spherical pores with a slightly greater mean Ar content of $0.3 \mathrm{ppm}$ in Inconel 718 specimens obtained by SLM. They suggest that even if the measured value seems to be very low, the Ar trapped in the structure may have a major influence on the mechanical properties and post-treatment. In high temperature conditions, as during HIP, machining or in various applications, the trapped Ar dilates (gas laws) and causes stresses that can lead to elastic or plastic deformations. They also indicate that only the pores without gas could be perfectly closed by an HIP. The spherical type defects are located more to the interior of the melt pools, while lack of melting and/ or matter type defects are to be found more on the boundaries of the melt pools and the overlapping of the layers (Fig. 10(b)).

Fig. 11 shows the micrography of the XY plane of specimen 29 obtained with a VED $=61.2 \mathrm{~J} / \mathrm{mm}^{3}$. A significant reduction in pores can be seen and above all of those of the lack of material or melt type as compared with specimen 31 (Fig. 10(a)). This reduction was observed for the three planes of specimen 12 and showed a good similitude in the level of porosity between the three planes. Fig. 11(b) meanwhile reports the level of porosity in relation to VED. This level of porosity varies from $0.48 \%$ to $1.35 \%$. As can be seen, VED has a significant impact on the level of porosity. Indeed, when VED increases, this leads to a reduction in the level of porosity. This observation seems coherent since 


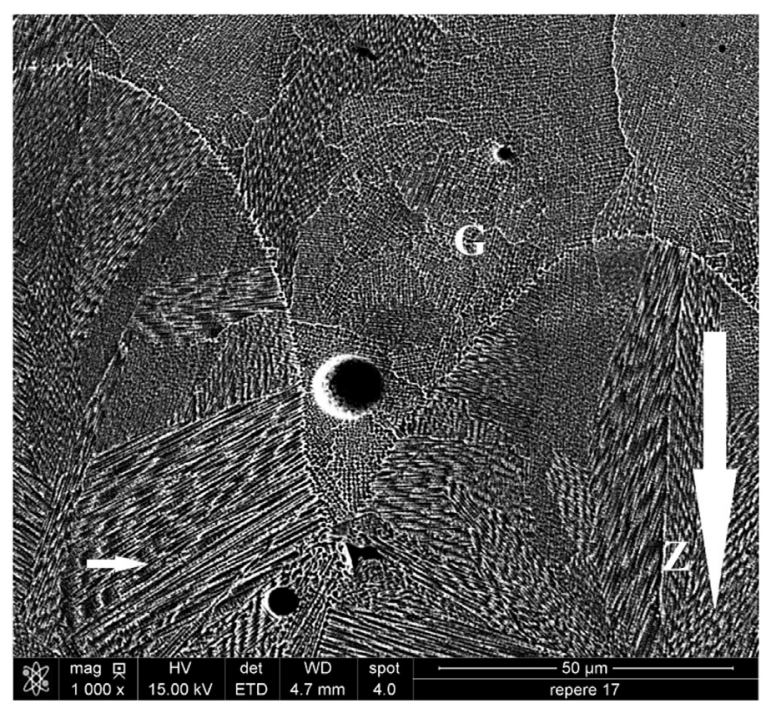

(a) Specimen $17, \mathrm{VED}=31.75 \mathrm{~J} / \mathrm{mm}^{3}$

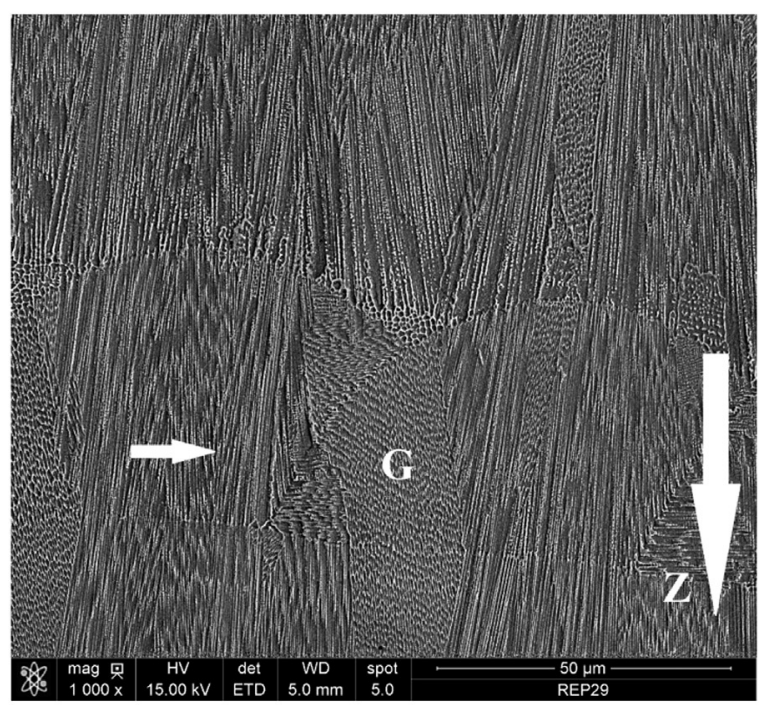

(b) Specimen 29, VED $=61.2 \mathrm{~J} / \mathrm{mm}^{3}$

Fig. 9. SEM micrographs of XZ plane showing columnar cellular (G) and fine dendrites (shown by arrow). $\mathrm{Z}$ is build direction.

greater energy is used to melt the powder, which has the effect of improving melting and a reduction in defects. Other authors have noted this phenomenon [30].

\subsubsection{SLM plus HIP and heat treatment}

The specimens were subjected to an HIP and a heat treatment (solution and ageing). The conditions were described above. HIP is mainly used to reduce porosity. However, Tillmann et al. [18] observe that HIP also modifies the microstructure of SLM Inconel 718: the microstructure no longer resembles the typical microstructure obtained by SLM, the grains are bigger, and they no longer have an orientation along the build axis. Solution treatment causes the transformation of one or more constituents into a solid solution and, by rapid cooling, these constituents are kept in that solution. Ageing treatment (conducted in two stages) causes hardening by precipitation. This treatment ensures germination and growth of the hardening phases $\gamma^{\prime}\left(\mathrm{Ni}_{3}(\mathrm{Ti}, \mathrm{Al})\right)$ and $\gamma^{\prime \prime}$ $\left(\mathrm{Ni}_{3} \mathrm{Nb}\right)$ in the matrix $\gamma$ up to a suitable volume fraction of around 15-20\% for $\gamma^{\prime \prime}$ [34], that confers its excellent mechanical properties on the alloy. Precipitation of the $\gamma^{\prime}$ and $\gamma^{\prime \prime}$ phases mainly arises during the first stage at $720^{\circ} \mathrm{C}$, while the function of the second stage at $620^{\circ} \mathrm{C}$ is mainly to ensure uniformity of the microstructure [35]. For the Inconel

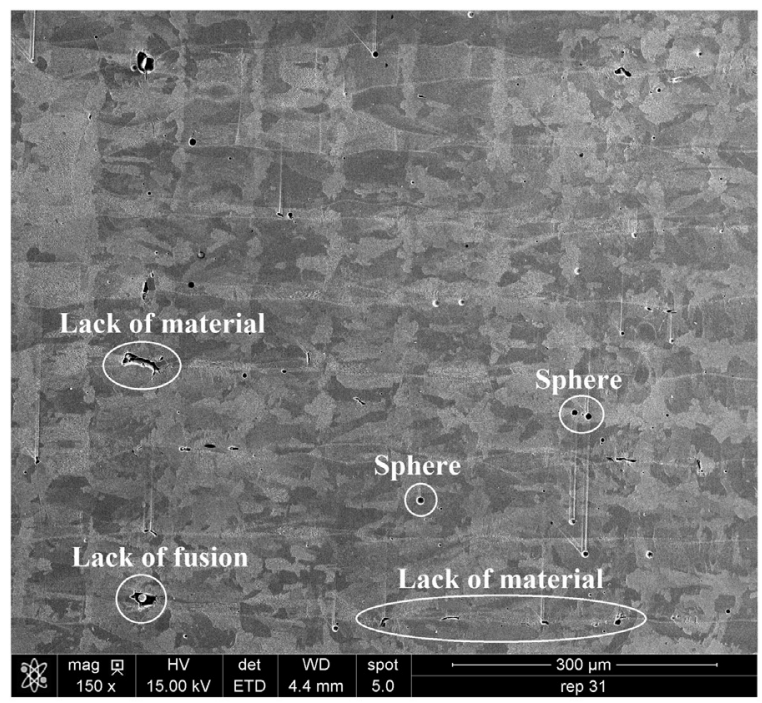

(a) Specimen 31, plane XY

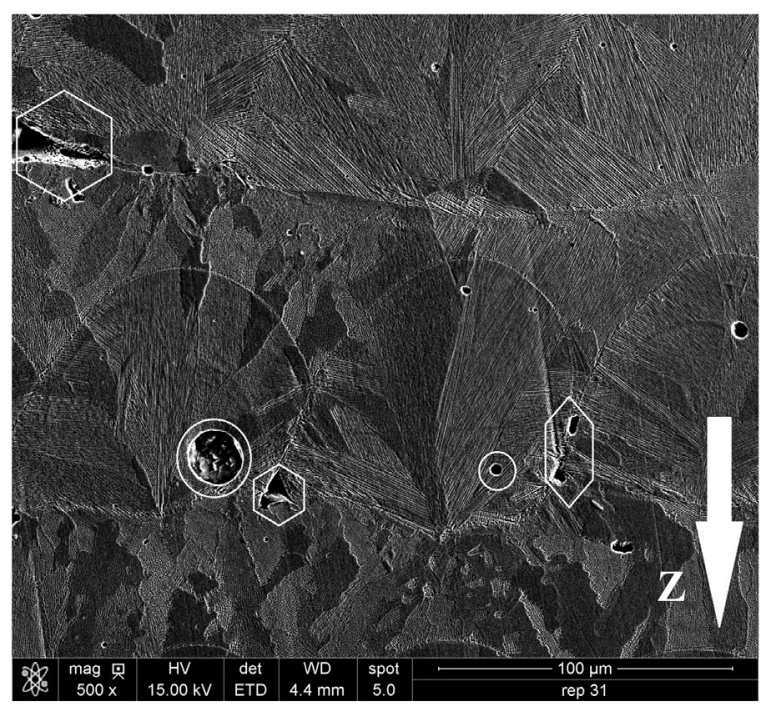

(b) Specimen 31, plane XZ

Fig. 10. SEM micrographs showing the different types of defects of SLMed Inconel 718. $\mathrm{VED}=31.75 \mathrm{~J} / \mathrm{mm}^{3}$. The circle indicates defects of the spherical type and the hexagon indicates the lack of fusion and/or material.

718 alloy, solution heat treatment and double ageing is needed [12].

Figs. 12 and 13 show the microstructure after HIP and a heat treatment. The dendritic microstructure has completely disappeared. The grain size is very heterogeneous and equiaxial and mainly columnar grains oriented in the build direction can be seen. The grain boundaries are mainly constituted of $\delta$ and MC carbides. All these observations concern the full set of specimens and the three planes. In the study by Chlebus et al. [12], they mention that heat treatment does not completely eliminate the texture, as it does not entirely change the columnar shape and crystallographic orientation of the solid solution grains.

The $\delta$ phase (Fig. 12, arrow 3) germinates mainly at the grain boundaries and its chemical composition is identical to that of the $\gamma^{\prime \prime}$ phase $\left(\mathrm{Ni}_{3} \mathrm{Nb}\right)$. It has an acicular and pebbly morphology. The growth of the $\delta$ phase can locally reduce the volume fraction of the $\gamma^{\prime \prime}$ phase $\left(\gamma^{\prime \prime}\right.$ becomes a source of $\mathrm{Nb}$ for $\delta$ ) and thus impairs local mechanical properties. However, when it is in a small quantity precipitated on the grain boundaries discontinuously, this phase can improve creep behaviour properties [36]. The MC carbides (Fig. 12, arrows 1 and 2) are predominantly block-shaped and are non-uniform distributed within 


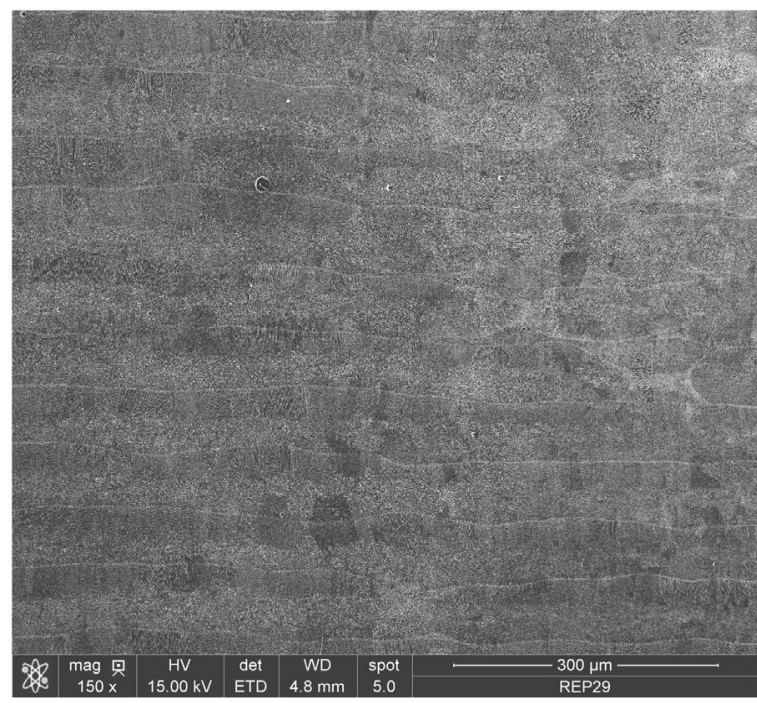

(a) Specimen 29, plane XY

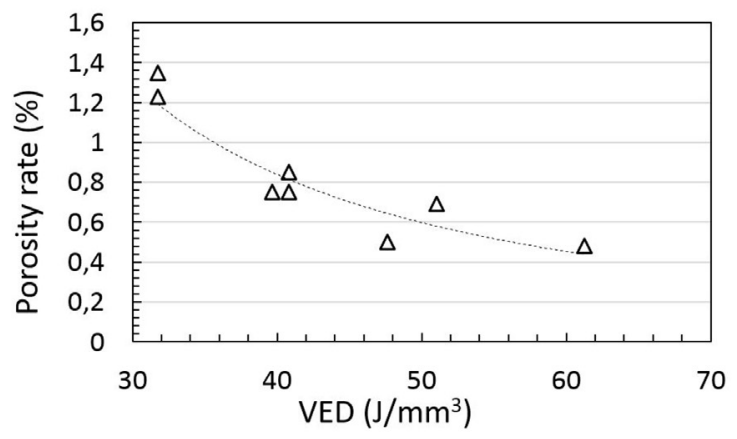

(b) XY plane porosity rate

Fig. 11. (a) SEM micrographs of specimen 29 with $V E D=61.2 \mathrm{~J} / \mathrm{mm}^{3}$. (b) $X Y$ plane porosity rate versus VED for all specimens.

the grain as well as at the grain boundaries. MC intragranular carbide can interfere with the movement of dislocations but gives low matrix strength to the strength produced by $\gamma^{\prime \prime}$ precipitation. This carbide, if it is on the surface of the part, can be a site of crack initiation or oxidation under thermal stresses, producing a notch effect unfavorable to fatigue [37]. The MC carbide at the grain boundaries promotes the transition from transgranular to intergranular fracture mode. When the carbides are closely distributed along the grain boundaries, the microcracks easily join together and facilitate the intergranular fracture. The MC carbides at grain boundaries, distributed in small quantities and of appropriate size, can limit the movement of grain boundaries, slow grain growth, and may increase creep and fatigue strength $[38,39]$. The $\gamma^{\prime}$ and $\gamma^{\prime \prime}$ phases cannot be observed under the SEM as their size is generally less than $20 \mathrm{~nm}$ [16].

On Fig. 13, a comparison is made between two specimens, one with a low VED and the other a high VED. It can be seen that the porosity has diminished very significantly. The level of porosity measured on the XY plane is less than $0.01 \%$ for all the specimens. The HIP has considerably reduced the size and level of porosity. The microstructure obtained after heat treatment is largely similar between the specimen with a low VED and a high VED. This shows that heat treatment largely erases the SLM microstructure obtained with different levels of VED and generates a new microstructure similar to that of all the specimens.

\subsection{Mechanical properties}

\subsubsection{Microhardness}

Among mechanical properties, microhardness is a major concern for

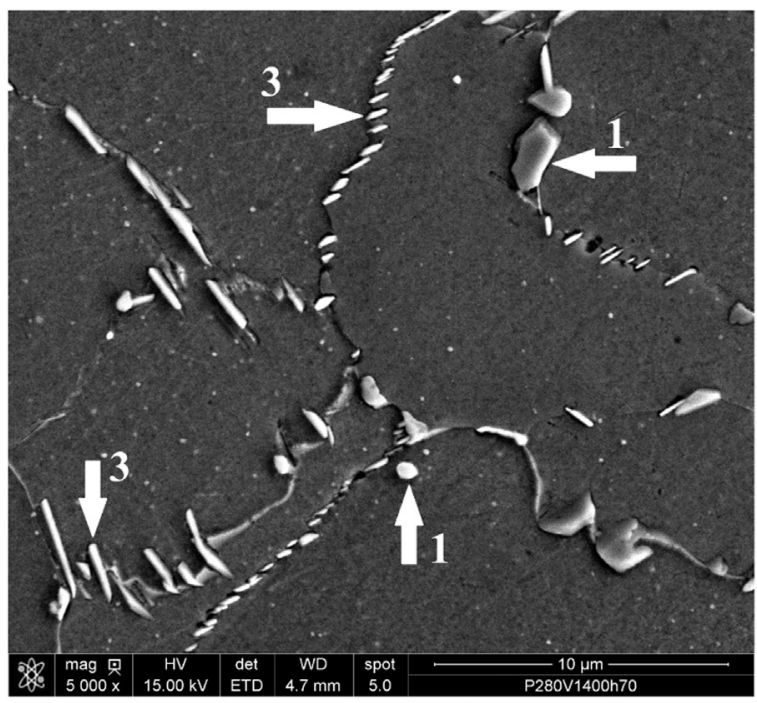

(a) Specimen 12, plane XY

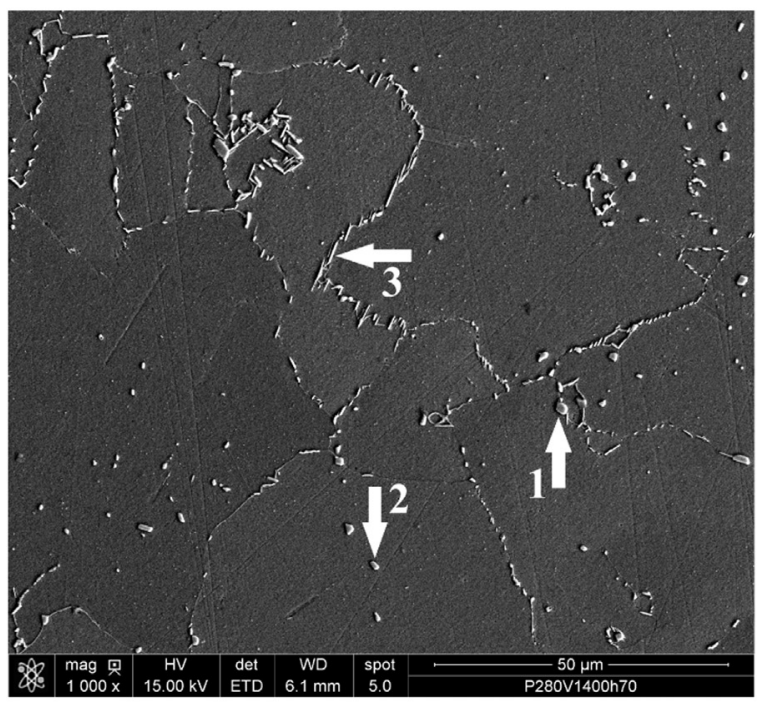

(b) Specimen 12, plane ZY

Fig. 12. SEM micrographs of specimen 12. (a) plane XY. (b) plane ZY. MC carbides on grain boundaries (arrow 1) and on the layer interface (arrow 2) accompanied by $\delta$-phase precipitates (arrows 3 ).

parts manufactured by SLM. Fig. 14 shows the microhardness results in relation to VED. Here, the results for as-deposited by SLM vary between 310 and 334 HV. No VED effect can be seen on these results. These levels of microhardness are corroborated by other studies $[16,31,12]$. It should be noted that the main source of hardening of Inconel 718 is the precipitation of the $\gamma^{\prime}$ and $\gamma^{\prime \prime}$ phases [40]. Another element that can increase hardening is porosity. In our study the porosity rate varies between $0.48 \%$ and $1.35 \%$. This variation remains relatively small to have an effect on microhardness. In view of the above analysis, the VED variation range $\left(31-61 \mathrm{~J} / \mathrm{mm}^{3}\right)$ studied here did not sufficiently precipitate these phases to observe a visible effect on the microhardness of the specimens before HIP + heat treatment. On this point, Jia et al. [30] observe an increase of microhardness (331.9-395.8 HV) for a range of variation of energy density ranging from 180 to $330 \mathrm{~J} / \mathrm{m}$. According to them, this improvement of the microhardness produced by the increase of energy density is the consequence of the decrease porosity rate, grains refinement and strengthening of precipitations and solid-solutions. According to our analysis of the results of Jia et al. the improvement in microhardness is due more to the porosity's decrease (from $26.4 \%$ to $1.6 \%$ ) caused by the increase in energy density. A heat 


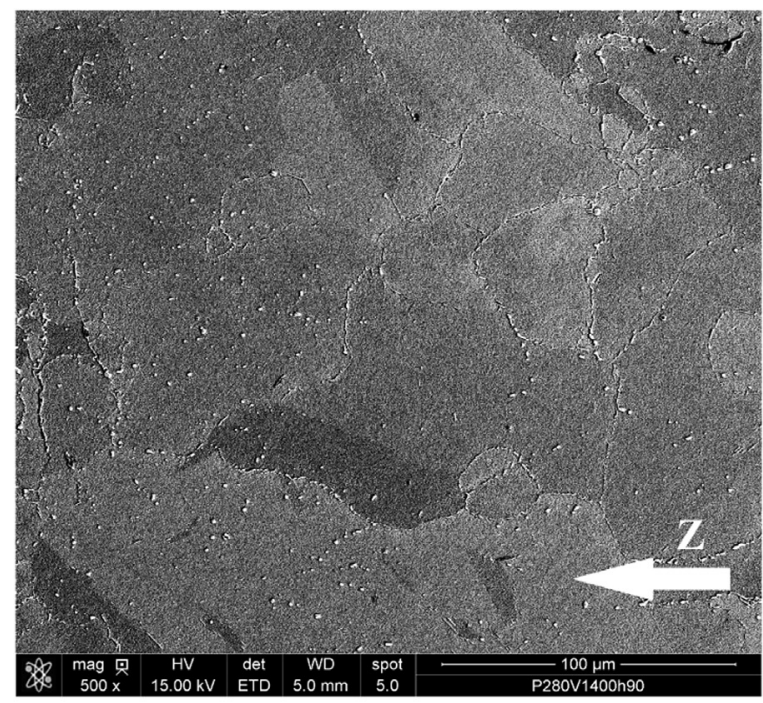

(a) Specimen 17 , plane $\mathrm{ZY}, \mathrm{VED}=31.75 \mathrm{~J} / \mathrm{mm}^{3}$

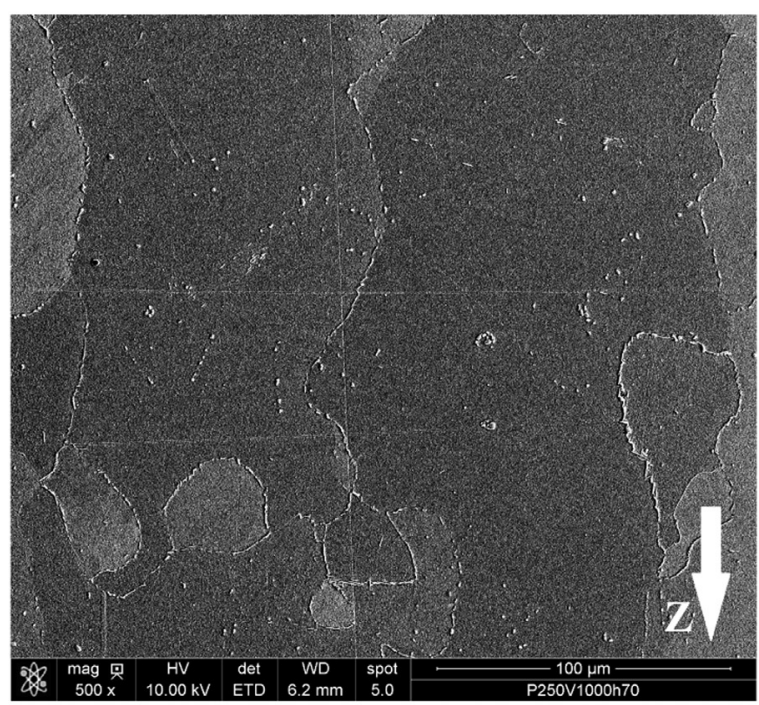

(b) Specimen 13, plane XZ, VED $=51 \mathrm{~J} / \mathrm{mm}^{3}$

Fig. 13. SEM micrographs of specimen 17 and $13 . \mathrm{Z}$ is build direction.

treatment is necessary to further enhance microhardness despite the way the material is obtained (by heating and very rapid cooling) that is generally beneficial for that quality. The results for HIP + HTed range between 461 and $492 \mathrm{HV}$. This remarkable improvement is mainly due to solution heat treatment and ageing that causes the precipitation of the $\gamma^{\prime}$ and $\gamma^{\prime \prime}$ phases in the matrix $\gamma$. These values correlate well with other studies using the same heat treatment or even better $[16,31,12]$. They are also higher than those obtained for a forged material having undergone heat treatment (430-460 HV [4]).

\subsubsection{Tensile properties}

Fig. 15 shows the results of tensile tests $\left(\sigma_{t}, \sigma_{0.2}, \epsilon_{f}\right)$ for series A $\left(0^{\circ}\right.$ : parallel to the Z-axis build) and series B ( $90^{\circ}$ : perpendicular to the Zaxis build). With series $\mathrm{A}$, the values vary for tensile stress $\left(\sigma_{t}\right)$ between 1334 and $1375 \mathrm{MPa}$, for the elastic limit $\left(\sigma_{0.2}\right)$ between 1084 and $1124 \mathrm{MPa}$ and for elongation at fracture $\left(\epsilon_{f}\right)$ between $17.5 \%$ and $20 \%$. With series B, the values vary for $\sigma_{t}$ between 1376 and $1392 \mathrm{MPa}$, for $\sigma_{0.2}$ between 1110 and $1136 \mathrm{MPa}$ and for $\epsilon_{f}$ between $18 \%$ and $25 \%$.

No significant visible effect of VED is seen on the tensile mechanical properties. However, a difference is noted between series A and series B for all tensile properties $\left(\sigma_{t}, \sigma_{0.2}, \epsilon_{f}\right)$. Tensile mechanical properties are

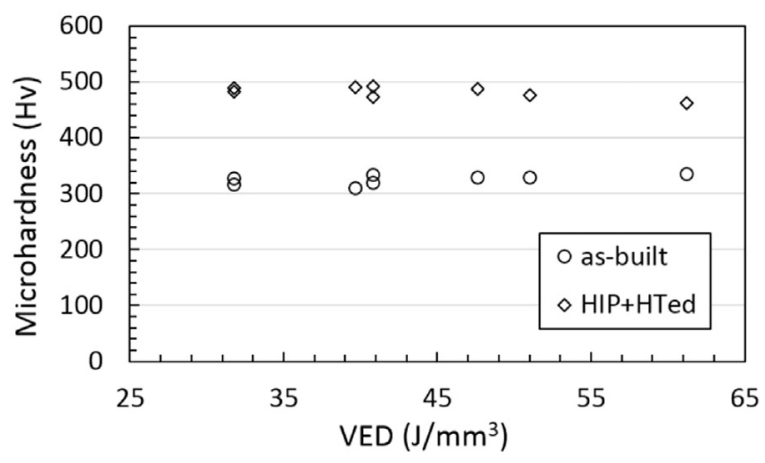

Fig. 14. Microhardness of SLM Inconel 718 specimens as-built and HIP + HTed.

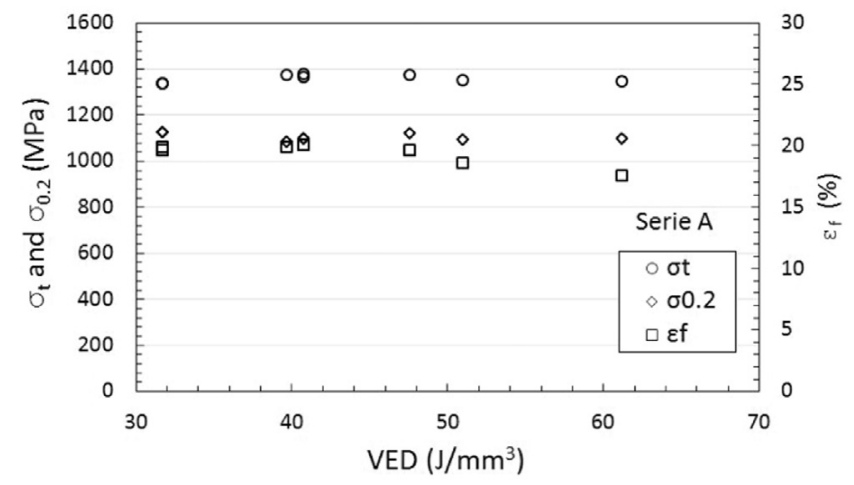

(a) Serie A

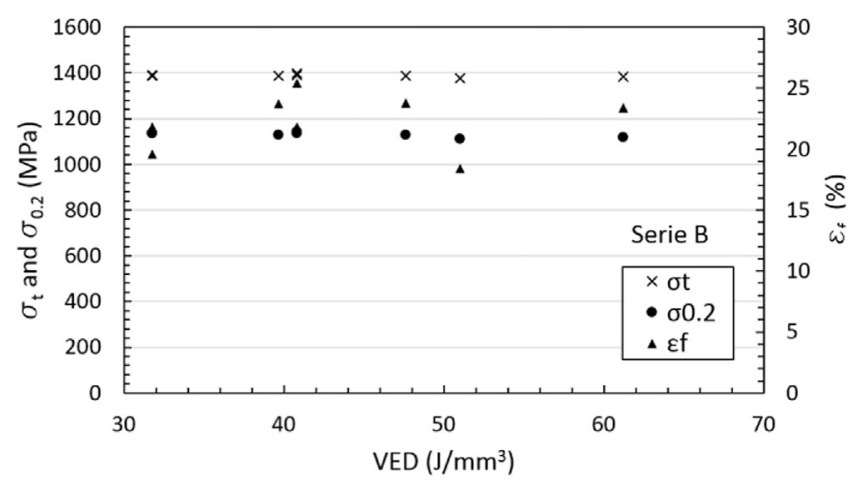

(b) Serie B

Fig. 15. Mechanical properties of Inconel 718 after HIP plus HTed. $\sigma_{t}$ is tensile strength, $\sigma_{0.2}$ is yield strength and $\epsilon_{f}$ is elongation at fracture.

distinctly better when the specimen is perpendicular to the Z-axis build (series B). According to Amato et al. [15], this difference between specimens parallel to and perpendicular to the build axis derives from the direction of the columnar grains. There are much more grain boundaries is perpendicular to the build axis for specimens at $90^{\circ}$ than parallel to the build axis for specimens at $0^{\circ}$. Other studies have observed the same difference $[12,41]$. Heat treatment played a perfect role in enhancing mainly the mechanical characteristics by precipitation of the $\gamma^{\prime}$ and $\gamma^{\prime \prime}$ phases.

The values for tensile mechanical properties are equivalent or even better as compared with those for other studies on Inconel 718 obtained by SLM and having used the same heat treatment [16,31,12]. As compared with forged and aged Inconel $718\left(\sigma_{t}=1100 \mathrm{MPa}\right.$, $\sigma_{0.2}=830 \mathrm{MPa}, \epsilon_{f}=31 \%$ ), these values are higher for $\sigma_{t}$ and $\sigma_{0.2}$ except for $\epsilon_{f}$. As for forged and aged Inconel $718\left(\sigma_{t}=1600 \mathrm{MPa}\right.$, $\left.\sigma_{0.2}=1400 \mathrm{MPa}, \epsilon_{f}=16 \%\right), \sigma_{t}$ and $\sigma_{0.2}$ are lower except for $\epsilon_{f}[42]$. 


\section{Conclusions}

The present study focused on the effects of SLM parameters through Volumetric Energy Density (VED) on porosity, microstructure and mechanical properties. The main conclusions can be summarised as follows:

- Roughness varies between 6.7 and $35 \mu \mathrm{m}$ on the top face of the cube and between 8.5 and $42 \mu \mathrm{m}$ on its side. The low velocities and powers generate reduced roughness while an increase in velocity and power leads to greater roughness. It is important to note that the quality of the final surface will depend mainly on the power/velocity relation.

- The SLM microstructure is a columnar dendritic microstructure oriented parallel to the build axis. This microstructure may enlarge through several layers and is made up of columnar grains with a cellular structure and columnar grains with very fine dendrites. The increase in VED leads to a microstructure with longer and tighter dendrites that are more oriented along the build axis.

- Several types of defects were observed: pores by lack of melting and/or of material and spherical pores. Mainly spherical pores were seen, located in the melt pools. Defects of the lack of melt and/or material type were located at the melt pool boundaries and the overlapping of layers. The level of porosity varied between $0.48 \%$ and $1.35 \%$. The increase in VED leads to a reduction in the level of porosity.

- After HIP and heat treatment, the dendritic microstructure has completely disappeared and conceded to a microstructure with equiaxial grains and mainly columnar grains oriented in the build direction. The grain boundaries were mainly composed of $\delta$ and MC carbides. The VED effect on the microstructure was no longer visible and it would appear that heat treatment removes a fair share of the SLM microstructure obtained with various levels of VED. The level of porosity was significantly reduced for all the specimens (less than $0.01 \%$ ) thanks to HIP.

- SLM microhardness varies between 310 and 334 HV. No VED effect was observed on these results. After heat treatment, microhardness increases remarkably and varies between 461 and $492 \mathrm{HV}$. Indeed, solution heat treatment and ageing leads to hardening by precipitation of the $\gamma^{\prime}$ and $\gamma^{\prime \prime}$ phases in the matrix $\gamma$.

- No significant visible effect of VED on tensile mechanical properties was observed. However, a difference was noted between parallel $\left(0^{\circ}\right)$ and perpendicular $\left(90^{\circ}\right)$ specimens in relation to the build axis. Heat treatment improved the tensile mechanical properties but removed the VED effect. These tensile results are better than those obtained for forging-annealing and slightly poorer than those for forging-ageing.

\section{Acknowledgements}

The research leading to these results has received funding from the French Single Inter-Ministry Fund, under ALMINCO Project agreement. The authors would like to thank the following institutions and companies for their contributions and support: Rgion Midi-Pyrnes and PRISMADD.

\section{References}

[1] H.Y. Zhang, S.H. Zhang, M. Cheng, Z.X. Li, Deformation characteristics of phase in the delta-processed Inconel 718 alloy, Mater. Charact. 61 (1) (2010) 49-53, https:// doi.org/10.1016/j.matchar.2009.10.003.

[2] M. Anderson, R. Patwa, Y.C. Shin, Laser-assisted machining of Inconel 718 with an economic analysis, Int. J. Mach. Tools Manuf. 46 (14) (2006) 1879-1891, https:// doi.org/10.1016/j.ijmachtools.2005.11.005.

[3] K.H. Song, K. Nakata, Microstructural and mechanical properties of friction-stirwelded and post-heat-treated Inconel 718 alloy, J. Alloy. Compd. 505 (1) (2010) 144-150, https://doi.org/10.1016/j.jallcom.2010.06.016.

[4] J.R. Davis, Nickel, Cobalt, and Their Alloys, ASM International, 2000 (google-
Books-ID: IePhmnbmRWkC, ISBN: 978-0-87170-685-0).

[5] T.M. Pollock, S. Tin, Nickel-based superalloys for advanced turbine engines: chemistry, microstructure and properties, J. Propuls. Power 22 (2) (2006) 361-374, https://doi.org/10.2514/1.18239.

[6] H. Attia, S. Tavakoli, R. Vargas, V. Thomson, Laser-assisted high-speed finish turning of superalloy Inconel 718 under dry conditions, CIRP Ann. 59 (1) (2010) 83-88, https://doi.org/10.1016/j.cirp.2010.03.093.

[7] J.P. Costes, Y. Guillet, G. Poulachon, M. Dessoly, Tool-life and wear mechanisms of CBN tools in machining of Inconel 718, Int. J. Mach. Tools Manuf. 47 (7) (2007) 1081-1087, https://doi.org/10.1016/j.ijmachtools.2006.09.031.

[8] J.E. Blanther, Manufacture of contour relief-maps, classification cooperative G09B29/12, 1892

[9] C.W. Hull, Apparatus for production of three-dimensional objects by stereolithography, 1986.

[10] E. Brandl, U. Heckenberger, V. Holzinger, D. Buchbinder, Additive manufactured AlSi10mg samples using Selective Laser Melting (SLM): microstructure, high cycle fatigue, and fracture behavior, Mater. Des. 34 (Suppl. C) (2012) S159-S169, https://doi.org/10.1016/j.matdes.2011.07.067.

[11] X. Gong, X. Wang, V. Cole, Z. Jones, K. Cooper, K. Chou, Characterization of Microstructure and Mechanical Property of Inconel 718 From Selective Laser Melting, 2015, V001T02A061. 〈http://dx.doi.org/10.1115/MSEC2015-9317〉.

[12] E. Chlebus, K. Gruber, B. Kuznicka, J. Kurzac, T. Kurzynowski, Effect of heat treatment on the microstructure and mechanical properties of Inconel 718 processed by selective laser melting, Mater. Sci. Eng.: A 639 (2015) 647-655, https:// doi.org/10.1016/j.msea.2015.05.035.

[13] Y. Lu, S. Wu, Y. Gan, T. Huang, C. Yang, L. Junjie, J. Lin, Study on the microstructure, mechanical property and residual stress of SLM Inconel-718 alloy manufactured by differing island scanning strategy, Opt. Laser Technol. 75 (Suppl. C) (2015) S197-S206, https://doi.org/10.1016/j.optlastec.2015.07.009.

[14] B. Vrancken, L. Thijs, J.-P. Kruth, J. Van Humbeeck, Heat treatment of Ti6al4v produced by Selective Laser Melting: microstructure and mechanical properties, J. Alloy. Compd. 541 (Suppl. C) (2012) S177-S185, https://doi.org/10.1016/j. jallcom.2012.07.022

[15] K.N. Amato, S.M. Gaytan, L.E. Murr, E. Martinez, P.W. Shindo, J. Hernandez, S. Collins, F. Medina, Microstructures and mechanical behavior of Inconel 718 fabricated by selective laser melting, Acta Mater. 60 (5) (2012) 2229-2239, https:// doi.org/10.1016/j.actamat.2011.12.032.

[16] Z. Wang, K. Guan, M. Gao, X. Li, X. Chen, X. Zeng, The microstructure and mechanical properties of deposited-IN718 by selective laser melting, J. Alloy. Compd. 513 (2012) 518-523, https://doi.org/10.1016/j.jallcom.2011.10.107.

[17] G. Strano, L. Hao, R.M. Everson, K.E. Evans, Surface roughness analysis, modelling and prediction in selective laser melting, J. Mater. Process. Technol. 213 (4) (2013) 589-597, https://doi.org/10.1016/j.jmatprotec.2012.11.011.

[18] W. Tillmann, C. Schaak, J. Nellesen, M. Schaper, M.E. Aydinoz, K.P. Hoyer, Hot isostatic pressing of IN718 components manufactured by selective laser melting, Addit. Manuf. 13 (Suppl. C) (2017) S93-S102, https://doi.org/10.1016/j.addma. 2016.11.006

[19] P.L. Blackwell, The mechanical and microstructural characteristics of laser-deposited IN718, J. Mater. Process. Technol. 170 (1) (2005) 240-246, https://doi. org $/ 10.1016 / \mathrm{j}$.jmatprotec.2005.05.005.

[20] T. Trosch, J. Strossner, R. Volkl, U. Glatzel, Microstructure and mechanical properties of selective laser melted Inconel 718 compared to forging and casting, Mater. Lett. 164 (2016) 428-431, https://doi.org/10.1016/j.matlet.2015.10.136.

[21] P. Hanzl, M. Zetek, T. Baksa, T. Kroupa, The influence of processing parameters on the mechanical properties of SLM parts, Procedia Eng. 100 (Suppl. C) (2015) S1405-S1413, https://doi.org/10.1016/j.proeng.2015.01.510.

[22] D. Gu, Y. Shen, Processing conditions and microstructural features of porous 3161 stainless steel components by DMLS, Appl. Surf. Sci. 255 (5, Part I) (2008) 1880-1887, https://doi.org/10.1016/j.apsusc.2008.06.118.

[23] V.K. Balla, J. Soderlind, S. Bose, A. Bandyopadhyay, Microstructure, mechanical and wear properties of laser surface melted Ti6al4v alloy, J. Mech. Behav. Biomed. Mater. 32 (Suppl. C) (2014) S335-S344, https://doi.org/10.1016/j.jmbbm.2013. 12.001 .

[24] M. Turker, D. Godlinski, F. Petzoldt, Effect of production parameters on the properties of IN 718 superalloy by three-dimensional printing, Mater. Charact. 59 (12) (2008) 1728-1735, https://doi.org/10.1016/j.matchar.2008.03.017.

[25] V.S. Sufiiarov, E.V. Borisov, I.A. Polozov, Selective Laser Melting of the Inconel 718 nickel superalloy, Appl. Mech. Mater. 698 (2015) 333-338, https://doi.org/10. 4028/www.scientific.net/AMM.698.333.

[26] D. Gu, Y. Shen, Effects of processing parameters on consolidation and microstructure of w-cu components by DMLS, J. Alloy. Compd. 473 (1-2) (2009) 107-115, https://doi.org/10.1016/j.jallcom.2008.05.065.

[27] A. Simchi, H. Pohl, Effects of laser sintering processing parameters on the microstructure and densification of iron powder, Mater. Sci. Eng.: A 359 (1-2) (2003) 119-128, https://doi.org/10.1016/S0921-5093(03)00341-1.

[28] L. Thijs, F. Verhaeghe, T. Craeghs, J.V. Humbeeck, J.-P. Kruth, A study of the microstructural evolution during selective laser melting of ti6al4v, Acta Mater. 58 (9) (2010) 3303-3312, https://doi.org/10.1016/j.actamat.2010.02.004.

[29] M. Sadowski, L. Ladani, W. Brindley, J. Romano, Optimizing quality of additively manufactured Inconel 718 using powder bed laser melting process, Addit. Manuf. 11 (Suppl. C) (2016) S60-S70, https://doi.org/10.1016/j.addma.2016.03.006.

[30] Q. Jia, D. Gu, Selective laser melting additive manufacturing of Inconel 718 superalloy parts: densification, microstructure and properties, J. Alloy. Compd. 585 (Suppl. C) (2014) S713-S721, https://doi.org/10.1016/j.jallcom.2013.09.171.

[31] D. Zhang, W. Niu, X. Cao, Z. Liu, Effect of standard heat treatment on the microstructure and mechanical properties of selective laser melting manufactured Inconel 
718 superalloy, Mater. Sci. Eng.: A 644 (Suppl. C) (2015) S32-S40, https://doi.org/ 10.1016/j.msea.2015.06.021.

[32] T. Vilaro, C. Colin, J.D. Bartout, L. Nazé, M. Sennour, Microstructural and mechanical approaches of the selective laser melting process applied to a nickel-base superalloy, Mater. Sci. Eng.: A 534 (Suppl. C) (2012) S446-S451, https://doi.org/ 10.1016/j.msea.2011.11.092.

[33] A. Mostafa, I. Picazo Rubio, V. Brailovski, M. Jahazi, M. Medraj, Structure, texture and phases in 3d printed IN718 alloy subjected to homogenization and HIP treatments, Metals 7 (6) (2017) 196, https://doi.org/10.3390/met7060196.

[34] M. Jambor, O. Bokuvka, F. Novy, L. Trsko, J. Belan, Phase transformations in nickel base superalloy INCONEL 718 during cyclic loading at high temperature, Prod. Eng. Arch. 15 (2017) 15-18, https://doi.org/10.30657/pea.2017.15.04.

[35] B. Max, Comportement mecanique et couplage mecanique-oxydation dans l'alliage 718: effet des elements en solution solide, INPT, Toulouse, 2014.

[36] B. Ter-Ovanessian, Etude comparative de differents superalliages base Ni pour ressorts de systemes de maintien (Ph.D. Thesis), INP Toulouse, Toulouse, 2011. [37] M.J. Donachie, S.J. Donachie, Superalloys: A Technical Guide, 2nd edition, ASM International, 2002 (google-Books-ID: vjCJ5pI1QpkC, ISBN: 978-0-87170-749-9).

[38] M. Sundararaman, P. Mukhopadhyay, S. Banerjie, Carbide precipitation in nickel base superalloys and their effect on mechanical properties, in: Proceedings of Superalloys 718, 625, 706 and Various Derivatives, 1997, 367.

[39] C.T. Sims, N.S. Stoloff, W.C. Hagel, Superalloys II: High-temperature Materials for Aerospace and Industrial Power, 2nd edition, Wiley-Interscience, New York, 1987.

[40] D. Keiser, H. Brown, Review of the physical metallurgy of Alloy 718.

[41] M. Ni, C. Chen, X. Wang, P. Wang, R. Li, X. Zhang, K. Zhou, Anisotropic tensile behavior of in situ precipitation strengthened Inconel 718 fabricated by additive manufacturing, Mater. Sci. Eng.: A 701 (2017) 344-351, https://doi.org/10.1016/j. msea.2017.06.098.

[42] Home|Special Metals Company. 